\title{
INSILICO STUDIES OF SULFUR-CONTAINING SHIKONIN OXIME DERIVATIVES AS INHIBITORS OF MGC 803 GASTRIC CANCER CELL LINE
}

\author{
S. Y. ISMAIL ${ }^{1}$, A. UZAIRU ${ }^{2}$, B. SAGAGI ${ }^{1}$
}

1 Department of Chemistry Kano University of Science and Technology, Wudil, Kano Nigeria, ysagir479@gmail.com

${ }^{2}$ Department of Chemistry, Ahmadu Bello University Zaria, Nigeria.

\begin{tabular}{l} 
A R T I C L E I N F O \\
\hline Article history: \\
Received 2018-10-03 \\
Accepted 2018-10-17 \\
Available online 2019-03-08 \\
\\
$k e y$ w o r d s \\
QSAR \\
Molecular docking \\
Shikonin oxime \\
Density Functional Theory \\
GFA
\end{tabular}

\begin{abstract}
A B S T R A C T
Quantitative structural activity relationship and molecular docking studies were performed to predict the anticancer activity of 41 sulfur-containing shikonin oxime derivatives. Quantum chemical calculations method (Density Functional Theory with B3LYP/6-31G* basis set) were used in optimising the studied molecules to find the lowest geometry. Genetic function algorithm was employed in selecting five relevent molecular descriptors that derived a quantitative relationship between the anticancer activity and the structural properties of the studied compounds. Based on the value of coefficient of correlation $R^{2} 0.833, R^{2}$ ext value of $0.64 R^{2}$ adj value of 0.799 and $Q^{2}$ value of 0.737 , the model was found to be robust, highly satisfactory and predictive. Docking study between the derivatives of sulfur-containing shikonin oxime and fibroblast growth factor receptor (5A46) revealed that compound number 24 has the highest binding energy of $-9.3 \mathrm{kcal} / \mathrm{mol}$ and all the other compounds has favourable binding affinity toward the target receptor.
\end{abstract}




\section{INTRODUCTION}

Gastric cancer also known as stomach cancer begins when a malignant cancer cells grows within the lining of the stomach; these cells has the ability to become tumor. Gastric cancer mostly occurs as a result of infection by a bacteria Helicobacter pylori with about $60 \%$ of all cases due to this bacteria, the risk is higher in some of the helicobacter pylori than others (Chang A.H. et al; 2010). Other risk factors may include smoking and dietary factors including Pickled vegetables and obesity (Gozalez C.A. et al; 2013).

Gastric cancer usually continues to develop in the human body without noticing it until it reaches its final stage, sometimes it even goes to the extent of spreading to other organs such as liver, lung, lining of the abdomen, lymph nodes and bones before its discovered this is the main reason of low survival rate of gastric cancer patient than many other types of cancers (Janet M. et al; 2010)

Signs and symptoms of gastric cancer at the early stage include abdominal pain, loss of appetite, heart burn and nausea while at the later stage of development, the sign and symptoms may include vomiting, blood in the stool, weight loss, difficulty in swallowing and change in skin and eye color (Rudon G. et al; 2007)

Quantitative structural activity relationship is a statistical model of correlation between a molecular descriptors and experimental activity of a compounds, these descriptors can be either two or three dimensional (Todeschini R. et al; 2009). This will undoubtedly help in understanding the interaction characteristics (non-bonding) between the active site of the target and the drug molecule (Li Y.P. et al;2013), while docking gives the detail of the binding conformation of the ligand with receptor, QSAR and molecular docking together will give an information that can be used in developing potential drug candidate (Jain S. et al; 2012)

The purpose of this study is to develop and establish a reliable, robust and highly predictive QSAR model that will serve as a guideline for designing highly potent inhibitor of MGC 803 gastric cancer cell line.

\section{MATERIALS AND METHODS}

\subsection{Data Sources:}

Forty one compounds derivatives of sulfur-containing shikonin oxime was obtained from the literature (Guang Huang et al., $2017)$, the inhibitory activity of the compounds $\left(\mathrm{IC}_{50}\right)$ expressed in $\mu \mathrm{M}$ were converted to $\mathrm{pIC}_{50}\left[\mathrm{pIC}_{50}=-\log \left(\mathrm{IC}_{50} \times 10^{-6}\right)\right]$ to reduce data dispersion and increase the linearity in the activity values of the compounds. The structure of the compounds and their activities are shown in Table 1.

\section{Table 1- Compounds and their pIC50}

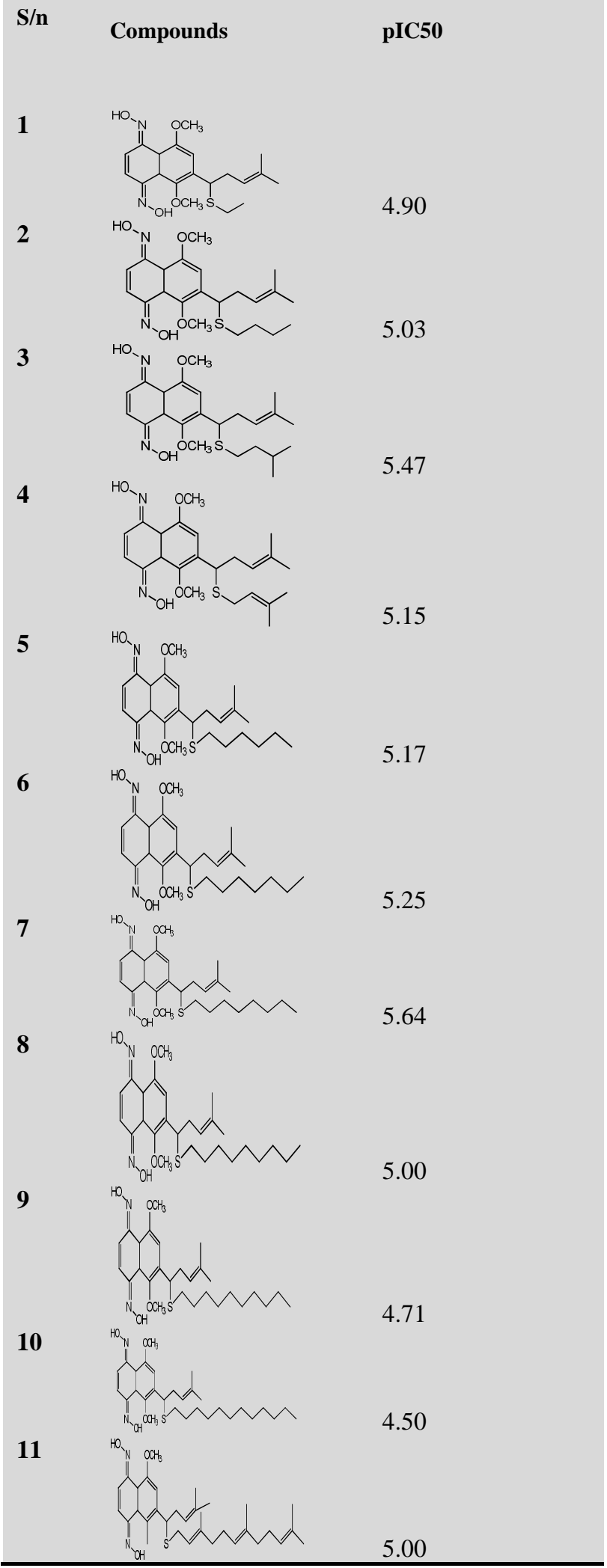



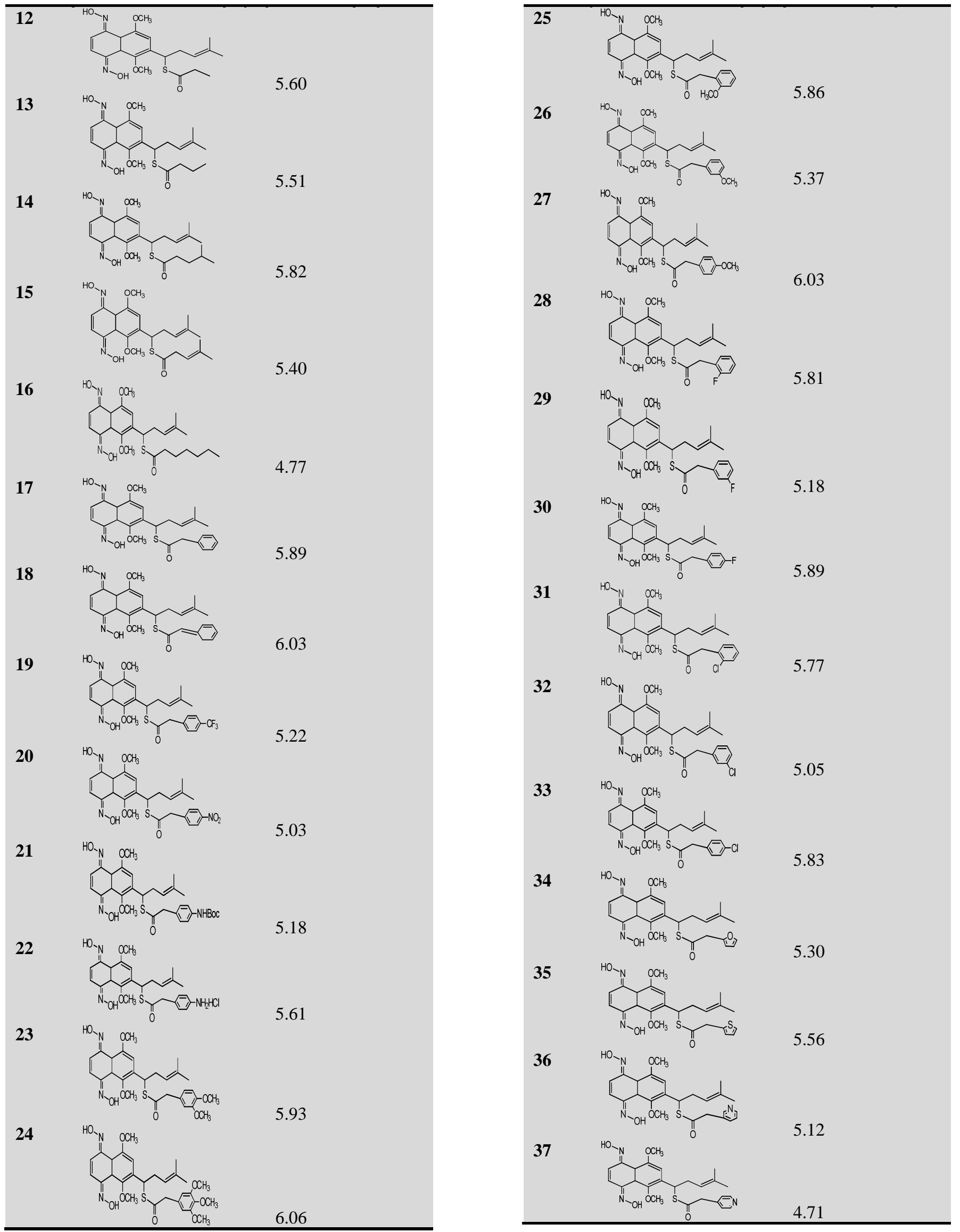


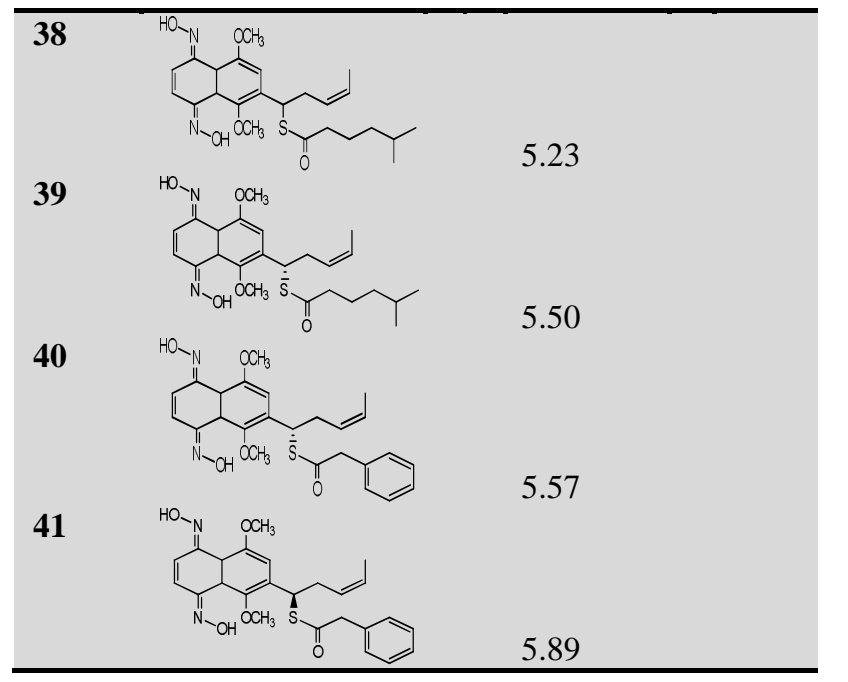

\subsection{Geometry optimization:}

The two-dimensional structure of the compounds were drawn using chemdraw software (cambridge soft 2010) and the conformation of the compounds was determined by using spartan software (spartan 14 v1.1.14) wave function software package. The structure of the compounds were first minimized by molecular mechanic force field (MMFF) to remove strain energy, Density functional theory with B3LYP and 6-31G* basis set was used in optimizing the molecules.

\subsection{Descriptors calculation:}

The optimized molecules were saved in sdf form and the descriptors of the optimized compounds was calculated by using the PaDEL software (PaDEL descriptor version 2.20).

\subsection{Data normalization and pre-treatment:}

The values of the descriptors were normalized, so as to give all the variables the same chance of influencing the model, noise and redundant data were removed by subjecting the data to pretreatment using data pre-treatment software (Shola A. E. et al; 2018 ].

$X=\frac{X_{1}-X_{\min }}{X_{\max }-X_{\min }}$

where $X_{1}$ is the value of each descriptor for a given molecule, $\mathrm{Xmax}$ is the maximum value for all the column of the descriptor $\mathrm{X}$, while $\mathrm{X}_{\min }$ is the minimum value for each column of descriptors $\mathrm{X}$.

\subsection{Data division:}

Kennard- Stone algorithm was employed in order to divide the data set into training set of 31 compounds and test set of 10 compounds, this is to ensure that all the points that will represent both training and test set compounds are evenly distributed within the whole descriptor space occupied by the entire data set (Arthur D. et al; 2016)

\subsection{Model development:}

Multi linear regression analysis was performed using genetic function approximation on material studio software with all the 31 training set compounds, the experimental activities of the compounds $\left(\mathrm{pIC}_{50}\right)$ are the dependent variables while the molecular descriptors are the independent variables.

\subsection{Internal validation of the model:}

The developed QSAR model was accessed by using friedman's lack of fit which is a measure of the fitness of the developed model. The formula for the friedman's lack of fit is

$L O F=\frac{S E E}{(1-(C+d \times p) / M)}$

where SEE means the standard error of estimation, $\mathrm{C}$ is define as the number of terms in the model, $\mathrm{d}$ is a user smoothing parameter, $\mathrm{p}$ is the number of descriptors that appears in the model and $\mathrm{M}$ is the amount of data in the training set. SEE is a measure of model's quality the lower the value of SEE the better the quality of the model. SEE is defined as

$$
S E E=\sqrt{\frac{\left(Y_{\text {exp }}-Y_{p r e}\right)^{2}}{N-P-1}}
$$

The square of the correlation coefficient $\left(\mathrm{R}^{2}\right)$ measure the power of the model to explain how the activity value of the molecules used in building the model varies. A satisfied model has an $R^{2}$ value of 1 , and the more the value of the $R^{2}$ deviate from 1 , the more the robustness of the model reduce that is the closer is the value of $\mathrm{R}^{2}$ to 1 the better the developed model (Adediran O. et al; 2018).

$R^{2}=1-\left[\frac{\sum\left(Y_{\exp }-Y_{\text {pred }}\right)^{2}}{\sum\left(Y_{\text {exp }}-Y_{\text {training }}\right)^{2}}\right]$,

where $Y_{\text {exp }}, Y_{\text {pre }}$ and $Y_{\text {training }}$ are the experimental, predicted and the mean experimental activities of the samples in the training set.

$\mathrm{R}^{2}$ values varies with increase in the number of descriptors, this makes $\mathrm{R}^{2}$ unreliable in measuring the fitness of the model thus $\mathrm{R}^{2}$ is adjusted for all the number of variables in the model and its defined as

$$
R_{A d j}^{2}=\frac{R^{2}-k(n-1)}{n-p+1}
$$

where $\mathrm{k}$ is the number of independent variables in the model and $\mathrm{n}$ represent the number of descriptors.

The strength of the equation of QSAR to predict activity of a compound was accessed by using leave-one-out crossvalidation method with the revised formula of

$$
Q^{2}=1-\left[\frac{\left.\sum Y_{\text {pred }}-Y_{\text {exp }}\right)^{2}}{\left.\sum Y_{\exp }-Y_{\text {training }}\right)^{2}}\right] \text {, }
$$


where $Y_{\text {pred, }} Y_{\text {exp }}$ and $Y_{\text {training }}$ are the predicted, experimental, and mean values of experimental activity of the training set.

\subsection{External validation:}

Internal validation of a model is employed in order to prove that the model has higher predictive ability and stability, however no real predictive capacity is shown for the external samples, this necessitate the need to ascertain the predictive ability(externally) and extrapolation arises (Bello A. S. et al; 2018). The predictive $R^{2}\left(R^{2}\right.$ test $)$ is calculated as follows

$R_{\text {test }}^{2}=1-\frac{\sum\left(Y_{\text {predtest }}-Y_{\text {exptest }}\right)^{2}}{\sum\left(Y_{\text {predtest }}-Y_{\text {training }}\right)^{2}}$,

where $Y_{\text {predtest }}$ and $Y_{\text {exptest }}$ are the predicted and experimental activity test set, while $Y_{\text {training }}$ represents mean values of experimental activity of the training set.

\subsection{Applicability Domain}

There is always need to verify the built QSAR model with regard to their applicability within the chemical domain of the compounds or data set applicability (Adedirin O. et al; 2018). Extrapolation of the leverage approach was used in defining the applicability domain and to identify all the outlier compounds, standardized residuals of each compounds was used in identifying of response outlier. Graphically, a plot of leverage values and standardized residuals was used to describe the domain of the model. The warning leverage $\left(\mathrm{h}^{*}\right)$ was calculated using $3(\mathrm{~m}+1) / \mathrm{n}$ (Bello A.S. et al; 2018) where $\mathrm{m}$ is the number of all the descriptors present in the model, $n$ is the number of training set compounds. when the graph was plotted, any compound that has its leverage value $\left(\mathrm{h}_{\mathrm{i}}\right)$ higher than $\left(\mathrm{h}^{*}\right)$ is considered to be an outlier compound and any compound that has leverage value $\left(h_{i}\right)$ lower than $\left(h^{*}\right)$ is considered to be an influential and reliable compound.

\section{MOLECULAR DOCKING STUDY}

This is a modeling technique used in predicting the interaction between the receptor and the ligand (Roy k. et al; 2015). Docking studies were performed between the fibroblast growth factor receptor PDB ID (5a46) and all the 41 sulfur-containing shikonin oxime derivatives in order to calculate the binding energy and study the interactions. The tools used in this study include HP beatsaudio computer system (intel corei5, 2.5GHZ processor, 12GB RAM, windows 8.1 operating system) pubchem data base, protein data bank, pyrex, autodock tools in autodock 4.3 program, vina wizard, and discovery studio.

\subsection{Preparation of Receptor}

The receptor were downloaded from protein data bank PDB ID $5 \mathrm{a} 46$ is a fibroblast growth factor receptor which is an attractive target in gastric cancer theraphy (Shilong Ying et al; 2017). All the complexes bounded to the receptor was removed using discovery studio, and the non essential water molecule was removed and polar hydrogen was added and the already prepared receptor was saved in PDB format.

\subsection{Ligand Preparation}

The optimized 41 sulfur-containing shikonin oxime derivatives was re-open on spartan software and be converted to PDB format and saved in that form.

\subsection{Docking of the Receptor with Ligand using Pyrex Software}

Docking of all the ligand was performed with pyrex software by selecting autodock as the docking engine, and the highest binding energy (most negative) was recorded as the binding energy. Visual analysis of the docking site was performed with discovery studio software.

\section{RESULT AND DISCUSSION}

\subsection{QSAR result}

Kernard-stone algorithm used in this study divided the data set into test set of 10 compounds and training set compounds of 31 , statistically the mean and the standard deviation of test set (5.32 and 0.001 ) were similar to that of training set (5.43 and 0.001), this shows that the test set compounds interpose within the training set compounds and they were statistically comparable. This prove that test set compounds are true reflection of the training set compounds.

After studying all the five GFA derived QSAR model, Model one was selected as the best model, this is due to its added statistical advantages than the remaining model, it has the highest value of $\mathrm{R}^{2}, \mathrm{R}_{\text {adj }}^{2}, \mathrm{R}_{\text {test }}^{2}, \mathrm{Q}^{2}, \mathrm{~F}_{\text {value }}$ and also the lowest value of $\mathrm{LOF}$ and experimental error.

$\mathrm{pIC}_{50}=-0.613504535 *$ SP-1 $+5.724670004 *$ FNSA-2 $+0.329775416 *$ GRAV-5 - 6.323694680* Weta2.unity + $4.216484623 *$ Weta1.eneg - 7.467079224 (8) $\mathrm{R}^{2}=0.833, \mathrm{R}_{\text {adj }}^{2}=0.799, \mathrm{Q}^{2}=0.737, \mathrm{~N}_{\text {training }}=31, \mathrm{~N}_{\text {test }}=10$, $\mathrm{LOF}=0.139, \mathrm{~F}_{\text {value }}=24.887, \mathrm{R}_{\mathrm{ext}}^{2}=0.640$. 
Table 2- Statistically Recommended value of parameters for generally acceptable QSAR

model

\begin{tabular}{|c|c|c|c|}
\hline $\mathbf{S} / \mathbf{N}$ & & Model 1 & Recommended \\
\hline 1 & $\mathrm{R}^{2}$ & 0.833 & $\geq 0.6$ \\
\hline & & & Very close to \\
\hline 2 & $\mathrm{R}_{\text {adj }}^{2}$ & 0.799 & $\mathrm{R}^{2}$ \\
\hline 3 & Q2 & 0.737 & $\geq 0.5$ \\
\hline 4 & LOF & 0.139 & Very low \\
\hline 5 & $\mathrm{~F}_{\text {value }}$ & 24.877 & High \\
\hline 6 & $\mathrm{R}_{\text {ext }}^{2}$ & 0.640 & $\geq 0.6$ \\
\hline 7 & ERROR & 0.144 & Very minimal \\
\hline 8 & $\mathrm{R}^{2}-\mathrm{Q}^{2}$ & 0.096 & $\leq 0.3$ \\
\hline
\end{tabular}

Source: Ravichandran et al; 2011.

Table 3- Descriptors used to validate the model (external validation)

\begin{tabular}{cccccccc}
\hline SP-1 & FNSA-2 & GRAV-5 & Weta2.unity & Weta1.eneg & \#VALUE & IC50 \\
& & & & & & \\
& & & & & & \\
18.01430 & -0.57168 & 82.42551 & 0.392184 & 0.468907 & 4.887375 & 5.03 \\
15.26399 & -0.76188 & 81.16399 & 0.365197 & 0.466819 & 5.231738 & 5.25 \\
16.42578 & -0.92616 & 84.69483 & 0.377139 & 0.500159 & 4.807939 & 4.50 \\
17.73031 & -1.07013 & 91.73115 & 0.472684 & 0.500013 & 4.898995 & 5.51 \\
16.81963 & -0.87448 & 88.46834 & 0.485645 & 0.482856 & 5.347444 & 5.40 \\
17.35764 & -0.86683 & 88.27556 & 0.389843 & 0.477045 & 5.578906 & 5.22 \\
14.37014 & -0.55986 & 78.14973 & 0.428935 & 0.471192 & 5.557921 & 5.93 \\
15.92578 & -0.82191 & 88.12056 & 0.577663 & 0.536540 & 5.726566 & 5.81 \\
15.40815 & -0.69349 & 80.53443 & 0.287364 & 0.496478 & 5.944403 & 5.85 \\
15.01430 & -0.67701 & 77.71371 & 0.393894 & 0.509359 & 4.730909 & 4.71 \\
\hline
\end{tabular}

Table 4- Definition and classes of all the descriptors used in this model.

\begin{tabular}{|c|c|c|c|}
\hline $\mathrm{S} / \mathrm{n}$ & Symbol & Name of descriptor & $\begin{array}{l}\text { Class of } \\
\text { descriptor }\end{array}$ \\
\hline 1 & SP-1 & Simple path, order 1 & $2 \mathrm{D}$ \\
\hline 2 & PNSA-2 & PNSA 2/total molecular surface area & $3 \mathrm{D}$ \\
\hline 3 & GRAV-5 & $\begin{array}{l}\text { Square root of gravitational index of all pairs of atoms (not just } \\
\text { bounded pairs) }\end{array}$ & $3 \mathrm{D}$ \\
\hline 4 & Weta2.unity & Directional WHIM, weighted by unit weights & $3 \mathrm{D}$ \\
\hline 5 & Weta1.eneg & $\begin{array}{l}\text { Directional WHIM, weighted by Mulliken atomic } \\
\text { electronegativities }\end{array}$ & $3 \mathrm{D}$ \\
\hline
\end{tabular}


Table 5 - Experimental, predicted and residual activities of training set compounds.

\begin{tabular}{|c|c|c|c|}
\hline $\mathbf{S} / \mathbf{n}$ & $\begin{array}{l}\text { Experiment } \\
\text { al activity }\end{array}$ & $\begin{array}{l}\text { Predicted } \\
\text { activity }\end{array}$ & Residual \\
\hline 1 & 4.90 & 5.07 & -0.17 \\
\hline 2 & 5.47 & 5.35 & 0.12 \\
\hline 3 & 5.15 & 4.99 & 0.16 \\
\hline 4 & 5.17 & 4.92 & 0.25 \\
\hline 5 & 5.64 & 5.69 & -0.05 \\
\hline 6 & 5.00 & 5.19 & -0.19 \\
\hline 7 & 4.71 & 4.84 & -0.14 \\
\hline 8 & 5.00 & 5.03 & -0.03 \\
\hline 9 & 5.60 & 5.44 & 0.16 \\
\hline 10 & 5.82 & 5.66 & 0.16 \\
\hline 11 & 4.77 & 5.15 & -0.38 \\
\hline 12 & 5.89 & 5.91 & -0.02 \\
\hline 13 & 6.03 & 5.99 & 0.03 \\
\hline 14 & 5.03 & 4.83 & 0.19 \\
\hline 15 & 5.18 & 5.39 & -0.22 \\
\hline 16 & 5.61 & 5.51 & 0.09 \\
\hline 17 & 6.06 & 5.82 & 0.24 \\
\hline 18 & 5.86 & 6.04 & -0.18 \\
\hline 19 & 5.37 & 5.39 & -0.03 \\
\hline 20 & 6.03 & 5.74 & 0.29 \\
\hline 21 & 5.18 & 5.07 & 0.11 \\
\hline 22 & 5.89 & 5.83 & 0.06 \\
\hline 23 & 5.77 & 5.97 & -0.20 \\
\hline 24 & 5.05 & 5.14 & -0.09 \\
\hline 25 & 5.30 & 5.26 & 0.04 \\
\hline 26 & 5.56 & 5.63 & -0.06 \\
\hline 27 & 5.12 & 5.11 & 0.01 \\
\hline 28 & 5.23 & 5.43 & -0.19 \\
\hline 29 & 5.50 & 5.47 & 0.03 \\
\hline 30 & 5.57 & 5.62 & -0.05 \\
\hline 31 & 5.89 & 5.81 & 0.08 \\
\hline
\end{tabular}

The robustness and predictive ability of the model was ascertained by the internal validation parameters of $R^{2}=0.83$ which satisfied the required $\geq 0.6$ and this means that the model can explain $83 \%$ of the variance in the anticancer activity of the data set against MGC 803 gastric cancer cell line, so also the model's cross validation coefficient $\left(\mathrm{Q}^{2}\right)$ of 0.737 also satisfied the recommended value of $\geq 0.5$ and the $\mathrm{R}^{2}$ adj value of 0.799 very close to $\mathrm{R}^{2}$ confirm the predictive ability of the developed model. likewise the lower residual value of the activity of training set compounds in table 5 and linearity of the plot of predicted and experimental activity of training set compounds in figure 1also confirm the predictive capacity of the model.

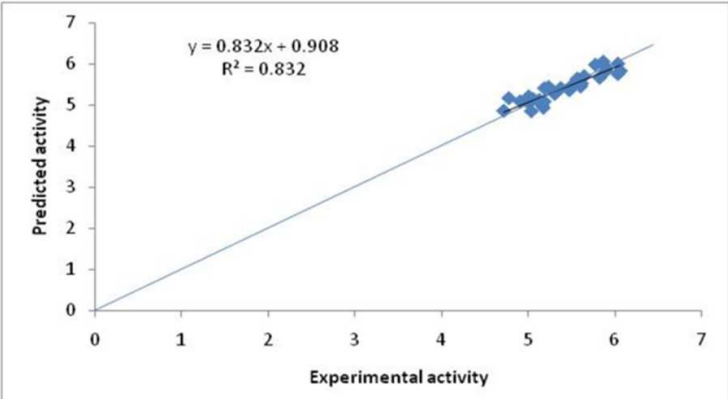

Figure 1- Plot of experimental vs predicted activities of training set compounds.

The external validation of the model with $\mathrm{R}^{2}$ ext value of 0.64 which satisfied the recommended value of $\geq 0.6$ and also the low residual values of the test set compounds as shown in table 6 and the linearity of the plot between the experimental and predicted activity of the test set compounds in figure 2 also confirm the predictive ability of the model. furthermore, the plot of predicted activity value against the standardized residuals in figure 3 showed a symmetric and random distributions of data points to the right and to the left of standardized residuals value $=0$ with all the points fall within range of standardized residuals value of -2.5 to +2.0 further confirming the robustness and predictive ability of the model.

Table 6 - Experimental, predicted and residual activities of test set compounds.

\begin{tabular}{llll}
\hline $\mathbf{S} / \mathbf{n}$ & $\begin{array}{l}\text { Experiment } \\
\text { al activity }\end{array}$ & $\begin{array}{l}\text { Predicted } \\
\text { activity }\end{array}$ & $\begin{array}{l}\text { Residual } \\
\mathbf{1}\end{array}$ \\
5.03 & 4.89 & 0.14 \\
$\mathbf{2}$ & 5.25 & 5.23 & 0.02 \\
$\mathbf{3}$ & 4.50 & 4.81 & -0.31 \\
$\mathbf{4}$ & 5.51 & 4.89 & 0.61 \\
$\mathbf{5}$ & 5.40 & 5.35 & 0.05 \\
$\mathbf{6}$ & 5.22 & 5.58 & -0.36 \\
$\mathbf{7}$ & 5.93 & 5.56 & 0.37 \\
$\mathbf{8}$ & 5.81 & 5.73 & 0.08 \\
$\mathbf{9}$ & 5.83 & 5.94 & -0.11 \\
$\mathbf{1 0}$ & 4.71 & 4.73 & -0.02 \\
\hline
\end{tabular}

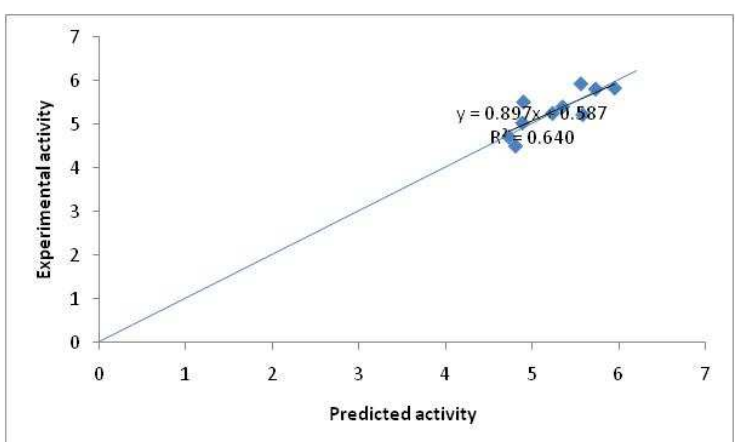

Figure 2- Plot of experimental vs predicted activities of test set compounds. 


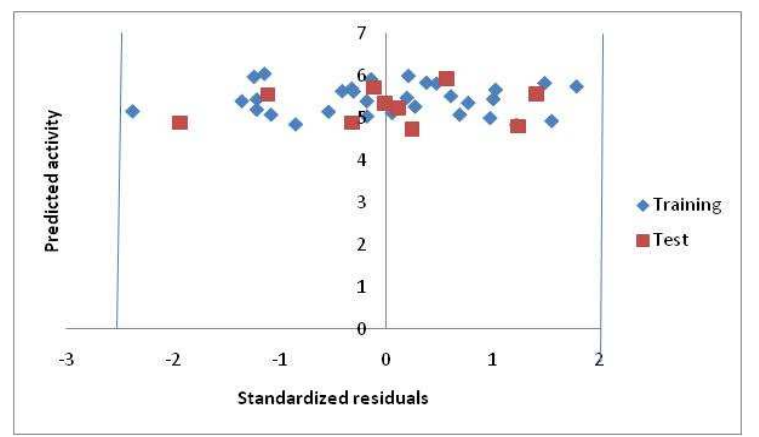

Figure 3: a plot of predicted activity vs standardized residuals

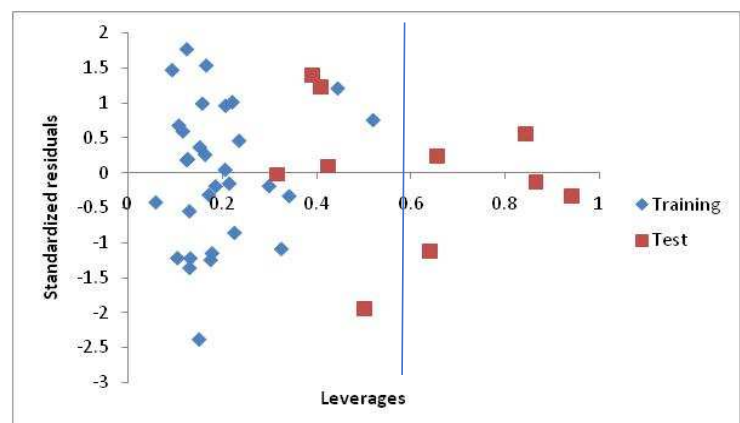

\section{Figure 3: A plot of standardized residual vs activity leverage values (William's plot).}

Nevertheless, no matter how significant, robust and thoroughly valid a QSAR model might be, it cannot reliably be predicted for the whole universe of chemical but for only those within its applicability domain. With warning leverage of $\left(h^{*}\right)$ value of 0.58 calculated using $3(\mathrm{~m}+1) / \mathrm{n}$ in this study, it was found out that 5 of the molecules has leverage value higher than the warning leverages and are considered to be outlier compounds while 36 of the total 41 data set compounds representing $88 \%$ has their leverage values less than the warning leverages $\left(h^{*}\right)$, this implies that $88 \%$ of the compounds can be reliably predicted within the chemical domain of the data set compounds.

\subsection{Molecular docking result:}

Molecular docking studies were carried out between all the 41 sulfur-containing shikonin oxime derivatives and the fibroblast growth factor receptor PDB ID 5a46, all the compounds show favorable binding affinity toward the receptor as shown in table 7 , with binding energy ranging between $-6.5 \mathrm{kcal} / \mathrm{mol}$ to $9.3 \mathrm{kcal} / \mathrm{mol}$ with exception of compounds 2 and 12 with binding energy of $-3.1 \mathrm{kcal} / \mathrm{mol}$ and $-2.3 \mathrm{kcal} / \mathrm{mol}$ respectively. Compound number 24 has the highest binding energy of -9.3 $\mathrm{kcal} \mathrm{mol}$ and 16 numbers of various interaction including both hydrogen and hydrophobic followed by compound number 21 with binding energy of $-8.9 \mathrm{kcal} / \mathrm{mol}$ and 10 numbers of various interactions including both hydrogen and hydrophobic than compound number 30 with binding energy of $-8.8 \mathrm{kcal} / \mathrm{mol}$ and
11 numbers of various interaction including hydrostatic interactions in addition to hydrogen and hydrophobic.

Table 7 - Compounds and their binding

\begin{tabular}{ll} 
SCore & \\
C1 & -7.2 \\
C2 & -3.1 \\
C3 & -7.5 \\
C4 & -7.4 \\
C5 & -7.7 \\
C6 & -7.4 \\
C7 & -7.5 \\
C8 & -6.6 \\
C9 & -6.8 \\
C10 & -6.7 \\
C11 & -7.2 \\
C12 & -2.3 \\
C13 & -7.1 \\
C14 & -6.5 \\
C15 & -6.9 \\
C16 & -7.4 \\
C17 & -7.2 \\
C18 & -7.4 \\
C19 & -7.2 \\
C20 & -7.4 \\
C21 & -8.9 \\
C22 & -7.7 \\
C23 & -7.6 \\
C24 & -9.3 \\
C25 & -6.9 \\
C26 & -7.1 \\
C27 & -6.8 \\
C28 & -7.1 \\
C29 & -7.3 \\
C30 & -8.8 \\
C31 & -7.3 \\
C32 & -8.2 \\
C33 & -6.9 \\
C34 & -6.7 \\
C35 & -7.4 \\
C36 & -7.0 \\
C37 & -7.1 \\
C38 & -6.5 \\
C39 & -7.3 \\
C40 & -7.7 \\
\hline
\end{tabular}


Table 8 - Various types of interactions, binding distances, binding energy and total number of interactions of best 3 compounds
$\mathrm{S} / \mathrm{n}$
Hydrogen bond
Hydrophobic interactions
Electrostatic
Binnding
Total
interactions
energy
number of
$(\mathrm{kcal} / \mathrm{mol})$
interactions

\begin{tabular}{|c|c|c|c|c|c|}
\hline $\mathrm{C} 24$ & $\begin{array}{l}\text { O-Lys482(2.97) } \\
\text { OH-Glu486(2.07) } \\
\text { O-Asn586(2.63) } \\
\text { O-Asn568(2.91) } \\
\text { OH-Arg627(2.11) } \\
\text { OH-Glu486(2.31) } \\
\text { O-Gly485(3.10) }\end{array}$ & $\begin{array}{l}\text { C-Ala512(3.78) } \\
\text { C-Ala512(4.02) } \\
\text { C-Leu484(4.82) } \\
\text { C-Ala512(4.97) } \\
\text { C-Val492(4.24) } \\
\text { C-Leu630(4.96) } \\
\text { C-Tyr563(5.18) } \\
\text { C-Leu484(5.33) }\end{array}$ & None & -9.3 & 15 \\
\hline C21 & $\begin{array}{l}\text { OH-Lys655(1.88) } \\
\text { OH-Asp623(2.10) } \\
\text { O-Leu644(3.91) }\end{array}$ & $\begin{array}{l}\text { C-Arg622(4.31) } \\
\text { C-Leu644(4.57) } \\
\text { C-Leu516(4.06) } \\
\text { C-Leu528(3.45) } \\
\text { C-Leu528(4.77) } \\
\text { C-His621(5.14) } \\
\text { C-Ala625(4.81) }\end{array}$ & None & -8.9 & 10 \\
\hline C30 & O-Arg627(3.55) & $\begin{array}{l}\text { C-Ile545(3.74) } \\
\text { C-Leu484(3.92) } \\
\text { C-Leu484(3.91) } \\
\text { C-Tyr563(5.06) } \\
\text { C-Asp641(4.27) } \\
\text { C-Glu531(4.81) }\end{array}$ & $\begin{array}{l}\text { C-Lys514(3.92) } \\
\text { C-Glu531(3.96) } \\
\text { C-Asp641(4.10) } \\
\text { C-Met535(5.12) }\end{array}$ & -8.8 & 11 \\
\hline
\end{tabular}

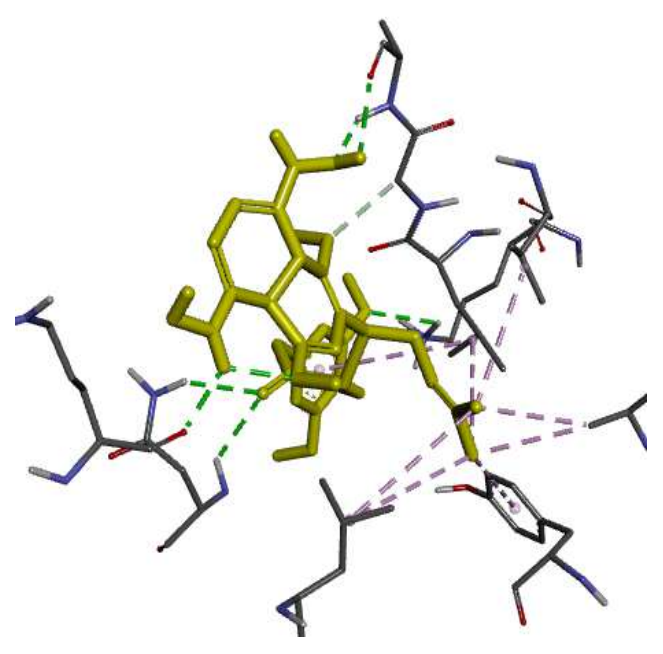

Figure 5A

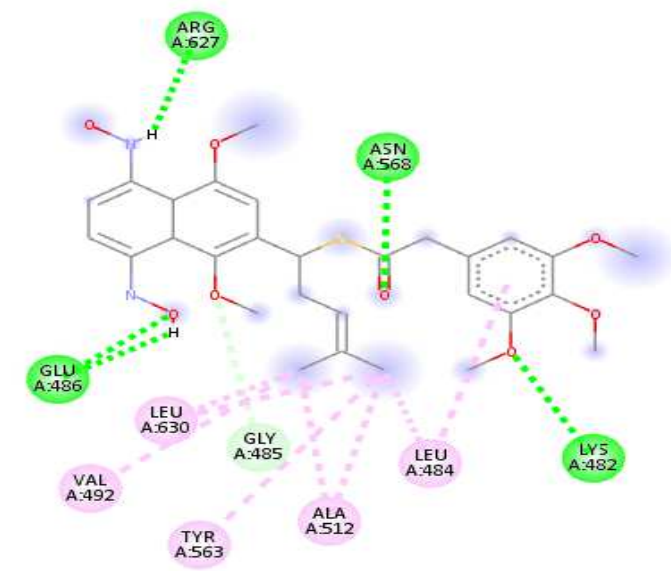

Figure 5B 


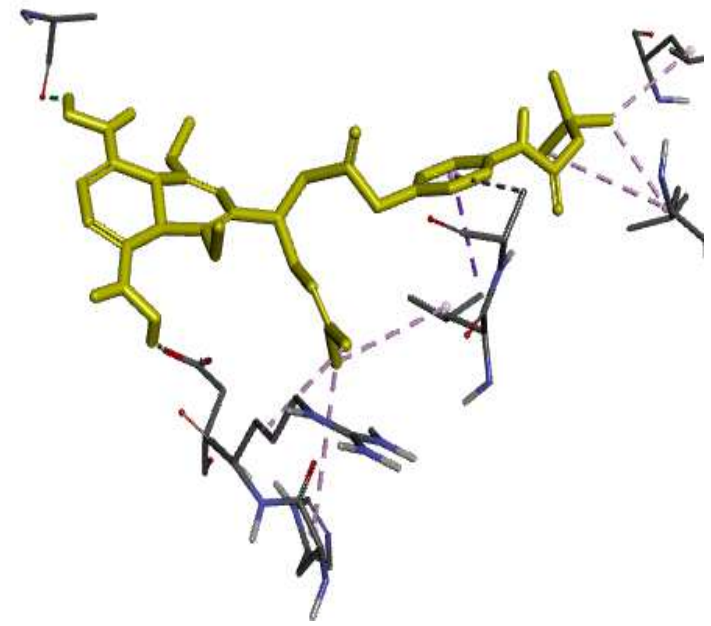

Figure 6A

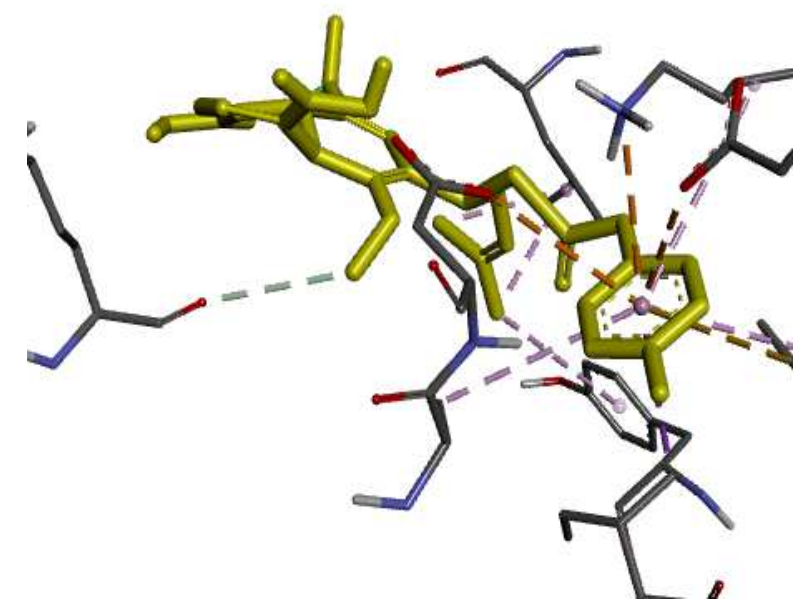

Figure 7A

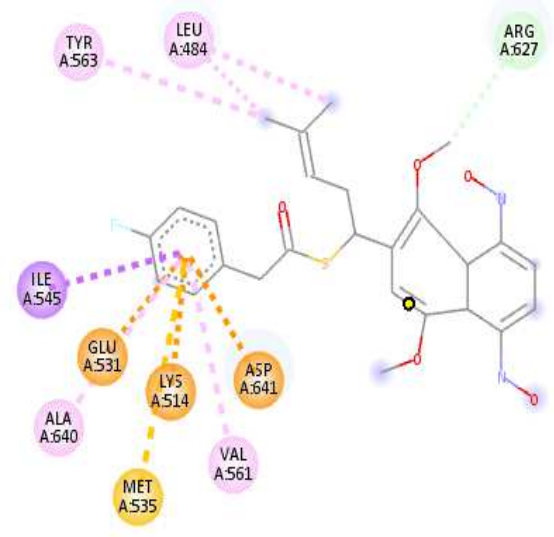

Figure 6B

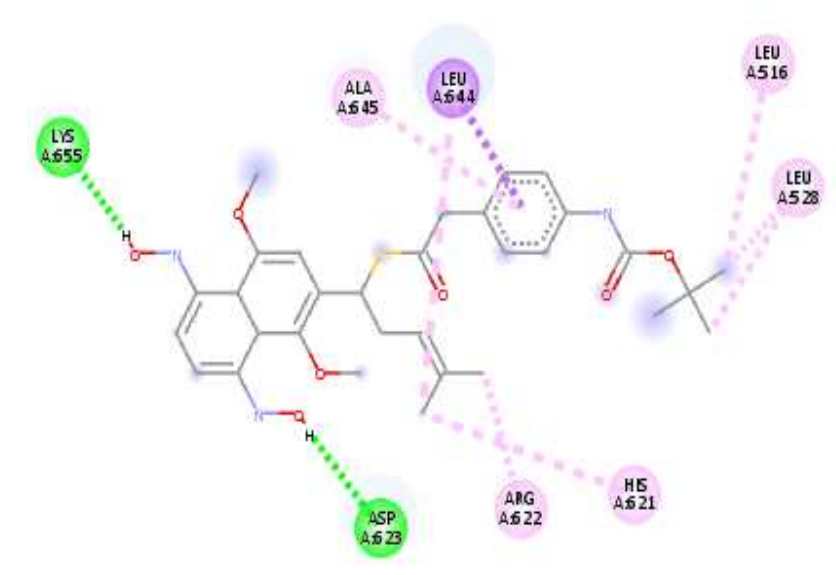

Figure 7B

Figure 5A, 6A and 7A 3D interactions of compounds number 24, 21 and 30 respectively. Figure 5B, 6B and 7B 2D interactions of compounds number 24, 21 and 30 respectively.

\section{CONCLUSION}

Five QSAR models were generated in this study, model one with added statistical advantages or significance than the others were chosen and it has $\mathrm{R}^{2}$ value of $0.833, \mathrm{R}^{2}$ adj value of 0.799 , $\mathrm{Q}^{2}$ value of 0.737 and $\mathrm{R}^{2}$ ext value of 0.64 and all of these parameters met the minimum value of QSAR model validation for generally accepted QSAR model which lead to establishing of the robustness, predictive ability and significance of the model, the descriptors SP-1, FNSA-2, GRAV-5, Weta2.unity and Weta1.eneg were found to have an influence on the studied compounds. Molecular docking studies carried out shows that all the compounds have favorable binding affinity toward the target receptor with compound number 24 having the highest binding energy of $-9.3 \mathrm{kcal} / \mathrm{mol}$ with 16 numbers of various interactions followed by compounds numbers 21 and 30 with binding energy of $-8.9 \mathrm{kcal} / \mathrm{mol}$ and $-8.8 \mathrm{kcal} / \mathrm{mol}$ and 10 and 11 numbers of various interactions respectively. The highest binding energy of compound number 24 shows that this research is in an agreement with literature (Guang Huang et al; 
2017) as it is the most active compound reported from the literature.

\section{Acknowledgement}

We wish to acknowledge All the authors of literatures consulted during this study. We also wish to acknowledge the management of Kano University of Science and Technology Wudil, Ahmadu Bello University Zaria, Bayero University Kano, Dr Sabiu Suleiman, Dr Aminu Nasir and Hauwa Abubakar Hakimi for their technical support and advise

\section{REFERENCES}

ADEDIRIN, O; UZAIRU, A; SHALLANGWA, G.A; ABECHI, S.E. QSAR studies on derivatives of quinazoline-4(3H)-ones with anticonvulsant activities. The journal of engineering and exact sciences JCEC, Vol 04 N. 02 (2018).

ARTHUR, D; UZAIRU, A; MAMZA, P; ABECHI, S; SHALLANGWA G. In silico modeling of cytotoxic behavior of anti-leukemia compound on HL-60 cell line. Journal of the Turkish chemical society, section A: chemistry. 2016, 3(2):147-158.

BELLO, A.S; UZAIRU, A; SHALLANGWA, G.A; IBRAHIM, A. Insilico studies of some indole derivatives as anti-hepatitis $\mathrm{c}$ drug. Journal of engineering and exact sciences JCEC, Vol 04 N. 02 (2018).

CHANG, A.H; PARSONNET, J. (2010) Role of bacteria in oncogenesis. clinical microbiology reviews 23 (4):837-857. doi 10.1128/CMR.00012-10.

GONZALEZ, CA; SALA, N; ROKKAS, T; SALA, ROKKAS; (2013). Gastric cancer: epidemiologic aspects. Helicobacter. 18 (supplement 1): 34-38.

GUANG, H; HUI, Z; QING, M; QI-JING, Z; JIN-YUN, D; BAO-QUAN, Z; SHAO-SHUN, L. "Synthesis and biological evaluation of sulfur-containing shikonin oxime derivatives as potential antineoplastic agent". European journal of medicinal chemistry. 2017 nov 14. 143(2018) 166-181.

JAIN, S; GHATE, M; BHADORIYA, K; BARI, S; CHAUDHARI, A; BORSE, J. 2D, 3D QSAR and docking studies of 1, 2, 3 thiadiazole thioacetanilides analogues as potent HIV-1 non-nucleoside reverse transcriptase inhibitors Org Med Chem Lett, 2012;2:1

JANET, M; CASSIO, LYN; RICHARD M GLASS. Stomach cancer, JAMA network doi 10.1001/jama.30317.1771.

KENNARD, R,W; STONE, L.A. Computer aided design of experiments. Technometrics, 11(1), 137-148, 1969.

LI, YP; WENG, X; NING, FX; OU, J-B; HOU, J-Q; LUO, HB; HUANG, S-L. 3D QSAR studies of azaoxoisoaporphine, oxoaporphine and oxoisoaporphine derivatives as anti-AChE and anti-
AD agents by the CoMFA method. $\mathrm{j}$ mol Graph Model, $2013 ; 41: 61-67$.

RAVICHANDRAN, V; RAJAK, H; JAIN, A; SIVADASAN, S; VARGHESE, C.P; KISHORE-AGRAWAL, R. Validation of QSAR models-strategies and importance. International Journal of Drug Design and Discovery. 2011 July 01. 2 511-519.

ROY, K; SUPRATIC, K; RUDRA, N. Understanding the Basics of QSAR for Application in Pharmaceutical Sciences and Risk Assessment. 2015 April 3. chapter 10 pp 257-425.

RUDON, G; RAYMOND, W. (2007) Cancer biology (4th edition). Oxford university press. p. 223 ISBN 9780195175431

SHILONG, YING; XIAOJING, DU; WEITAO, FU; DI, YUN; LIPING, CHEN; YUEPIAO, CAI; QING, XU; JIANZHANG, WU; WULAN, LI; GUANG, LIANG. Synthesis, biological evaluation, QSAR and molecular dynamics simulation studies of potential fibroblast growth receptor 1 inhibitors for treatment of gastric cancer. European journal of medicinal chemistry. volume 127, 15 February 2017, pages 885-899.

SHOLA, A.S; UBA, S; UZAIRU, A. Insilico study for investigating and predicting activities of 1,2,4-triazole derivatives as potent tubercular agents. The journal of engineering and exact sciences JCEC, vol. 04 N.02 (2018).

TODESCHINI, R; CONSONNI, V; GRAMATICA, P. Chemometrics in QSAR. Comprehensive chemometrics. ChemBiochem data anal, 2009; 4: 129172.

YAP, C.W. PaDEL-descriptor: An open source software to calculate molecular descriptors and fingerprints. J. Comput. Chem, 2011. 32(7): p. 1466147 